Perspective, part of a Special Feature on The Science and Practice of Ecology and Society

\title{
Puntacana Ecological Foundation and the Scaling of Sustainable Tourism Development
}

\author{
Stephen M. Uzz:o ${ }^{1,2}$
}

\begin{abstract}
The terms "sustainable tourism," "ecotourism," "sustainable development," and "sustainability" have all been applied to various aspects of the global tourism industry to indicate that operators in those industries have accounted for the environmental, social, and economic impacts of their endeavors on the geographical regions within which they function. However, there has been increasing criticism that models for sustainable tourism do not account well for the long-term impacts of resort operations and how they scale in terms of local and regional economies, environmental footprint, and effect on local culture. The case of the Puntacana Ecological Foundation is cited here as a successful example of how locally focused, adaptive, and integrated sustainability efforts may provide useful models for the scaling of durable sustainable tourism activities in other regions and globally.
\end{abstract}

Key Words: Caribbean; conservation; environmental studies; sustainable development; sustainable tourism

\section{INTRODUCTION}

In this treatise I describe Grupo Puntacana's work in sustainable tourism through the Puntacana Ecological Foundation (FEPC) and its programs in the Punta Cana region of the Dominican Republic (DR). These programs provide an exemplar that both informs the field and provides transferable models for scalable, integrated sustainable tourism with global significance. Formalization of these models and development of systemic indicators based on them may be useful in advancing the field of sustainable tourism and could have implications for sustainable development writ broadly.

\section{INTEGRATED SUSTAINABLE TOURISM}

The United Nations (UN) defines integrated sustainable tourism development as fitting into a balanced, systemic, and dynamic development model in which overarching regional and even global social and environmental issues are addressed through a local and/or regional lens (UNEP 2009). Global social and environmental issues of tourism development share positive and negative dimensions, but each case has specialized needs and conditions peculiar to the local and regional cultural and natural ecosystems. Attributes the UN defines as essential for integrated sustainable tourism development include balancing social and economic objectives with environmentally sound management; emphasizing long-term viability and sustainability of tourism, environments, and cultures rather than continuous growth or quick profit; and being adaptive to fluctuations in economic, ecological, and cultural trends. We can summarize these attributes through understanding the systemic relationship among the environmental, economic, and cultural subsystems and their interdependencies as shown in Figure 1.
Fig. 1. Sustainable Community Model in which the economy depends on society, which depends on the environment. (@ 2010 Maureen Hart. Source: www. Sustainablemeasures.com)

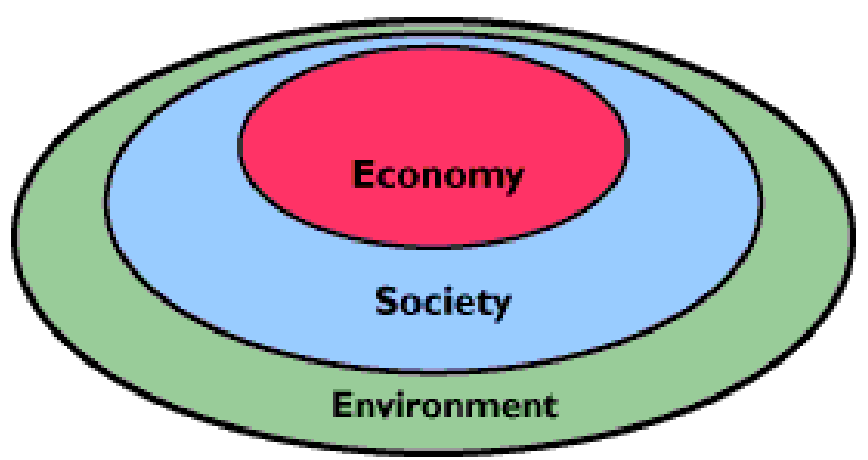

Environmental systems are particularly important to tourism because the enduring appeal of tourism destinations often relies heavily on the quality of the natural environment in which a resort is situated. Economic systems that include resorts are typically characterized by for-profit enterprises that function within a competitive financial ecosystem. They may include shareholders and must compete among other entities in their market to remain viable. Realities of capitalist models of competition such as short-term stock price fluctuation, differentiation within a market, and being responsive to consumer choices can draw off resources that might be used to address issues related to long-term sustainability and to address imbalances with environmental and social impacts. 
Social systems are more accurately sociopolitical systems in which the resort entity must collaborate and negotiate with local, regional, or national governmental systems and attend to social norms of the society in which is it situated. Resorts are not autarkies. To be sustainable, they must be integrated into, and function within the surrounding social, cultural, and political systems. From the standpoint of socioeconomic systems, this means a kind of mutualism, in which, just as the resort brings in business investment and tourists, it is creating an infrastructure that uses local services; functions within, and advocates for balancing political objectives and profit motives. It further employs local populations while anticipating the growth of local communities through immigration both domestically and beyond. It is inevitable that resort operations will disrupt local culture and economies through displacing populations, highlighting income disparities and cultural differences, and introducing market needs that may not have previously existed, while supplanting traditional ones.

Sustainable tourism leverages these systems and their interconnectedness to simultaneously raise standards of living among the local populations, retrain and educate them to transition from indigenous economies to service economies while preserving cultural cohesion, and monitors the interchange among social, environmental, and economic needs; seeking pinch-points, identifying emerging problems, involving stakeholders, and making adjustments to maintain balance. It requires analysis, planning, and monitoring; and must take into account the greater regional, and even global environmental, social, political, and economic trends and needs. Frameworks for sustainable integrated tourism development are prevalent in the literature and have been established by a variety of organizations ranging from the United Nations (http://sustainabledevelopment.un.org/index. php?menu=243) to the Caribbean Tourism Organization (http://www.onecaribbean.org). However, increasingly, there is a realization that such frameworks need to better account for the ways tourism functions as part of complex adaptive systems and that the many intersecting and dynamic inputs and outputs can result in emerging, and difficult to predict, long-term outcomes (Liu 2003). Revising indicators to reflect this complexity shows in recent trends in modeling sustainable tourism development (Schianetz and Kavanaugh 2008, Hembd and Silberstein 2011).

\section{ENVIRONMENTAL AND SOCIAL IMPACTS OF TOURISM IN DOMINICAN REPUBLIC}

The growth of tourism, a vital economic sector for Caribbean nations has had direct and collateral impacts on both the environmental and social systems in DR, just as it has in other resort regions (Michelitsch 2001). These include:

- Shifts in markets from subsistence, agricultural (in the case of DR, primarily sugar cane plantations and cattle ranching) and mining, toward raw materials, supplies, and commodities that support resort operations.
- Growth of service sector economy along with disruption of local culture and migration of populations to tourist areas.

- Impacts of building, operations, recreational activities; and changes in population, consumption, and byproducts in sensitive, and in many cases threatened or endangered ecosystems.

DR has the most diverse combination of land and marine ecosystems in the Caribbean, ranging from subalpine conifer forest, to rainforest, to semiarid plain, to mangrove forest along the coast. The Punta Cana region consists mainly of dry coastal forest, terrigenous lime-sand beach and mangrove marshes, predominantly mixed red [Rhizophora mangle] and white [Laguncularia racemosa] mangrove, with upland lagoons mainly resulting from collapse in Karst limestone terrain. Beyond the beaches and mangrove habitats are extensive coral reefs and associated sea grasses. Reefs off Punta Cana straddle the Mona Passage, which separates the Atlantic Ocean from the Caribbean Sea. This creates two distinct and ecologically diverse reef systems: the Bavaro-Macao Reef and the Punta Cana-Juanillo Reef, making the region of particular interest from a marine diversity and ecosystems standpoint (Geraldes and Vega 2005).

Impacts in Punta Cana marine environment of special concern include coral reefs, beaches, and native fauna, including hawksbill sea turtles (Eretmochelys imbricata), native fish and crustaceans, which are affected by tourism, overfishing, and invasive species, such as lionfish (Pterois sp.). Terrestrial environments suffer from poorly regulated land use and development, resulting in deforestation, erosion, which also affects coral reefs through siltation, and desertification. Overuse of resources, such as freshwater, results in shortages, pollution, and saltwater intrusion. Aquifers are particularly vulnerable to pollution because of the high rate of percolation of surface contaminants through limestone.

It is worth noting that the rapid growth of tourism in Punta Cana has collaterally introduced a variety of endemic urbanization problems as workers migrate to the vicinity for employment. Veron emerged as an urban center and only transitioned from a "municipal tourism district," a kind of informal settlement that is not well recognized or supported by the federal government, to an official "municipal district" in 2010. Infrastructure has not kept up with population growth resulting in lack of: sanitation facilities, clean and wellregulated drinking water, solid waste disposal, and safe vehicular and pedestrian roadway conditions. Unusually, electricity is abundant and reliable, more so than in many other parts of DR, but is relatively expensive (Frane 2009). These are common problems of scale in growing resort communities. The process of identifying creative solutions to seemingly intractable problems is evident in many of the activities of FEPC and indicate that while one organization cannot solve 
all the problems of a region at the pace in which they emerge, they can be a wellspring of models that can be effective in identifying and testing solutions with broad applicability, that have the potential to address them over the long term.

\section{THE EVOLUTION OF PUNTA CANA AND ACTIVITIES OF GRUPO PUNTACANA}

Prior to the introduction of tourism to the region, the indigenous economy was primarily subsistence fishing, farming, and extensive charcoal production. Charcoal, the primary fuel, was produced in inefficient kilns and used in inefficient open stoves for cooking. The Punta Cana region consists mainly of dry subtropical forests, the primary source wood used in charcoal production, and unsustainable deforestation resulted both in habitat destruction and widespread shortages of charcoal in Punta Cana and throughout DR, making it a net importer of wood and fuel (Knudson et al. 1988). The way of life of the traditional population of the region was clearly not sustainable. Most residents of the region were classified by the DR government as squatters and lived without basic infrastructure or sanitary facilities.

Grupo Puntacana (GPC), a commercial resort development company, acquired land in easternmost DR and built the first commercial resort in the region during the early 1970s. From its inception, the developers had decided to use sustainable practices and become involved in supporting improvements to local infrastructure. The introduction of the tourist economy was accompanied by GPC's creation of housing, water, and waste infrastructure and an elementary school for the local population. The resort communities in Punta Cana continued to grow as land was sold to other resort operators. GPC built an international airport and reconstructed the resort buildings based on low environmental impact architecture using indigenous thatch roof techniques and native materials of the indigenous Sabal causiarum palm, locally known as palma cana.

\section{GRUPO PUNTACANA AND THE PUNTACANA ECOLOGICAL FOUNDATION}

In 1988, GPC set aside 1500 acres of lowland dry subtropical forest with freshwater lagoons as the Indigenous Eyes Ecological Park and Reserve (Figs. 2 and 3) and formed the Puntacana Ecological Foundation to run it. In 1998, GPC founded the Puntacana Foundation (FPC) to develop social and community programs in the region such as schools, clinics, vocational training programs, sustainable development, and exchange programs. Since that time, these two organizations have worked synergistically to initiate and integrate social and environmental programs that better the environmental quality and living standards for the region, the country, and serve as exemplars for existing and emerging resort communities worldwide. The GPC and its foundations were used as the exemplar in a study to determine the trajectory of Dominican resort tourism toward attaining the United Nations 2015, Millennium Development Goals. It is clear that the resulting "Dominican Model" has promise as a generalizable approach to achieving these goals (Sasidharan and Hall 2012). An important quality of the programs is demonstration of the utility of collaboration and cooperation among local initiatives and businesses (seeking synergistic agricultural activities such as fruit tree cultivation and beekeeping), and large-scale international initiatives, such as the Clinton Global initiative, the United Nations, Save the Children, and others, to deal with preserving fisheries, coral reefs, and regionally and globally endangered species such as the Ridgway's Hawk (Buteo ridgwayi) and Rhinoceros Iguana (Cyclura cornuta); along with developing integrated models for dealing with problems of rapid growth of peri-urban areas like Veron and the need to retrain populations for emerging shifts in employment. It is important to note that the effectiveness of these programs is a result of the guiding philosophy of the Foundation's work, which includes a socio-environmental systemic view; small scale piloting and scaling up of processes; and a generative view of program development.

Fig. 2. Entrance to the Indigenous Eyes Ecological Reserve. (C) Puntacana Ecological Foundation)

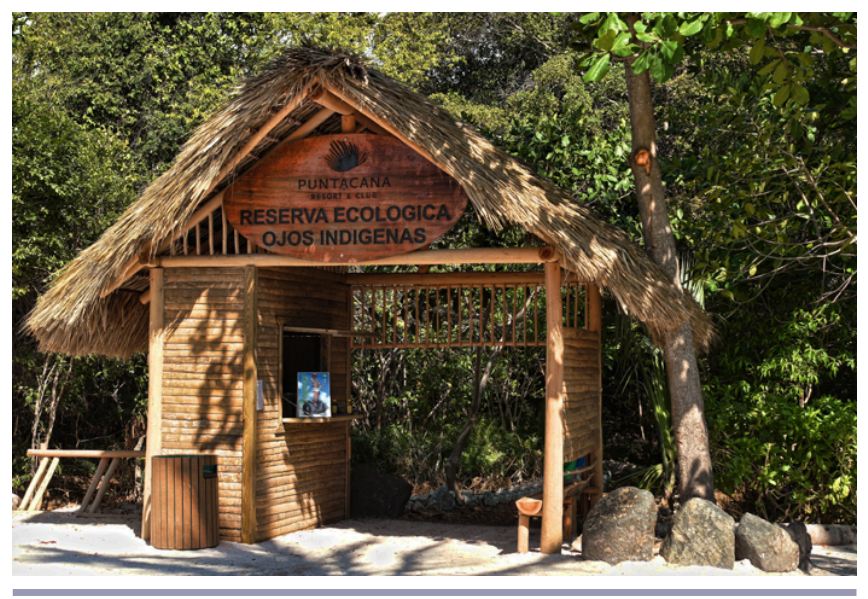

\section{FEPC PROGRAMS: DESCRIPTION AND IMPACT}

The Puntacana Center for Sustainability was formed to address environmental and social challenges related to tourism development in the Caribbean and globally. Their primary objective is to influence the development of sustainable tourism destinations through rational and renewable use of resources, doing leadership training in responsible global citizenship, expanding scholarship in sustainable practices, and facilitating knowledge transfer in the Caribbean Region. The Center includes a diverse and growing coalition of national and international institutions, including: 
Fig. 3. Map of Indigenous Eyes Ecological Reserve. () Puntacana Ecological Foundation)

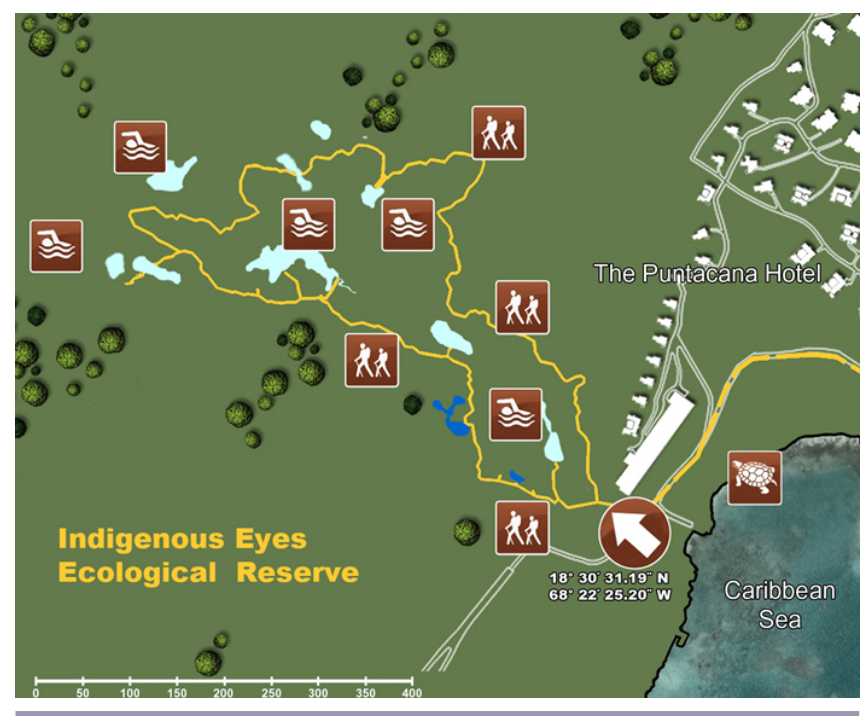

- Cornell University, which operates its Minorities in Research and Training program funded by NIH to support undergraduate research in biodiversity, along with undergraduate courses on ornithology from the Cornell Laboratory of Ornithology,

- Columbia University, which runs ecosystems courses in inquiry-based, field ecology for undergraduates,

- Harvard University, which runs the Consortium for Caribbean Biodiversity committed to improving scientists understanding of insects and plants of Hispaniola and the Caribbean, as well as running sustainable architecture courses for Harvard and Syracuse University,

- University of South Carolina, in which students do a hospitality research practicum with resort visitors, and

- Leiden University, which is doing archeological research in the nearby El Cabo area.

The Center is equipped with laboratories, offices, a library, classroom and living facilities (Figs. 4 and 5). The Center for Sustainability also houses the Caribbean Center for Education and Research, a base for Virginia Polytechnic Institute faculty to conduct research and instruct students on biodiversity, environmental and social sustainability, global issues in natural resources, and hotel and sustainable tourism management. Faculty and students take advantage of the Indigenous Eyes Reserve and the surrounding coastal region to study natural resources of the area. In the course of instruction, students work together with local organizations to solve social, technical, and environmental problems, including: Integrated cultural, language, and community service projects and field work; joint environmental camp and community service programs between American and Dominican 4-H teens; Engineers Without Borders projects in collaboration with the local Rotary Club to design and install water purification systems in Veron; land use and urban growth analyses and surveys for Veron; and design and implementation of composting systems and wastewater treatment facilities for resorts targeting zero waste.

Fig. 4. Main Center for Sustainability facility in Punta Cana. (@) Puntacana Ecological Foundation)

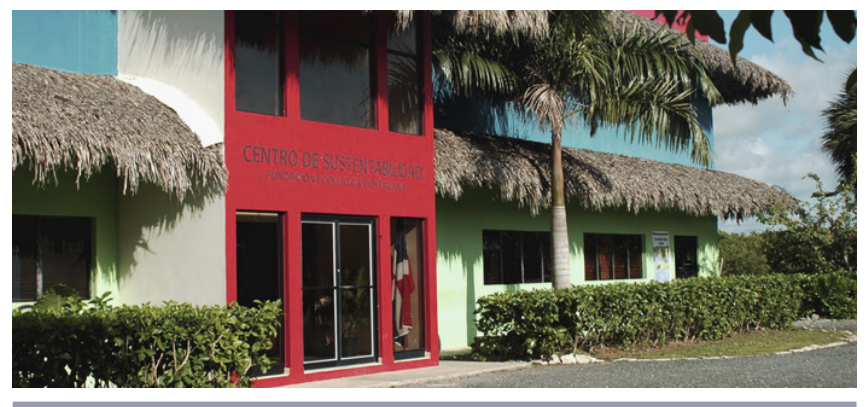

Fig. 5. Map of Ecological Foundation facilities. (@) Puntacana Ecological Foundation)

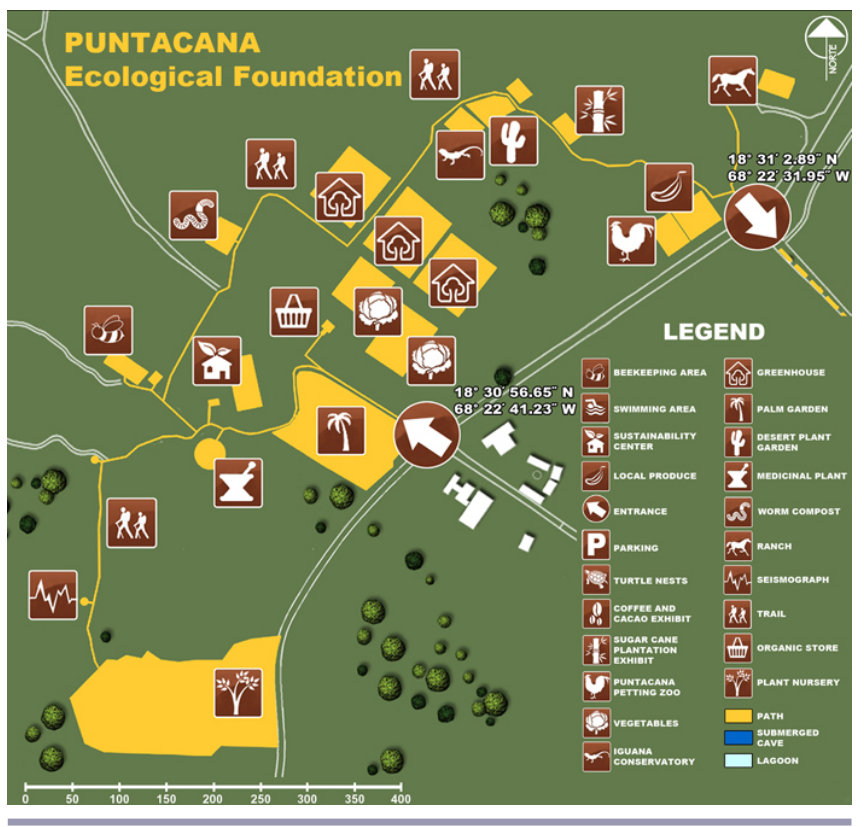

The Partnership for Ecologically Sustainable Coastal Areas is a public-private coalition represented by government agencies, private companies, local stakeholders, and 
international partners that provide technical and scientific expertise to test and implement integrated coastal management programs. For example, working with several national and international organizations, the Partnership organized a beachmonitoring program and patrols throughout the turtle egglaying season, resulting in the identification of nests for the hawksbill sea turtle a globally endangered species, and with the help of Puntacana Resort guests, residents and employees safely released over 580 hawksbill hatchlings in 2010. The hawksbill conservation program was then expanded to include other local beaches, other hotel chains and their guests in these monitoring initiatives. It is seeking ways to encourage future nesting by preserving and restoring native flora around beaches to provide better nesting habitat, and making changes in coastal lighting on and near beaches to encourage successful nesting behavior. The Partnership has also begun an awareness campaign about the illegal turtle shell trade, targeting tourists to reduce demand for turtle shell crafts. Hawksbill turtle shell is the primary material used in these products.

Another part of this partnership is seeking out and developing best practices and exchange programs based on successful conservation effort elsewhere in the region. They are finding ways to protect and restore declining populations of staghorn corals and their reef environments. Staghorn and elkhorn (Acropora sp.) corals habit and morphology make them a particularly important and vulnerable ecological coral reef asset and indicator of reef decline. They occur in shallow waters because of the presence of Symbiodinium and other photosynthetic algal symbionts, and their branching morphology makes them ideal protective habitat for prey fish species. They are also important to the large-scale calcium carbonate structure of reefs because they are fast-growing. In an effort to protect these endangered Caribbean corals, the partnership paired up with the University of Miami Rosenstiel School of Marine and Atmospheric Science and Counterpart International to develop in-water coral nurseries in Punta Cana's protected areas, then outplanting nursery-grown coral fragments back onto the reef to help reverse degradation by pollution, disease, siltation, human activity, and other threats. The program has grown into the second largest coral nursery in the Caribbean and now includes additional nurseries in Punta Rucia and Sosua, DR. The Foundation has full-time staff working on the project and leads workshops and volunteer opportunities to help promote the project in other tourist destinations around the country.

Coral reef efforts include protecting other endemic reef species. The spiny lobster (Panulirus argus) is important both ecologically to the coral reefs, as well as economically to DR and the Caribbean (Chavez 2007). Lobster fisheries throughout the Caribbean have been overexploited for many years and in combination with fishing and diving practices damages the reefs. The state of declining lobster populations throughout the Caribbean has resulted in a fishing ban during the spring reproductive season. Meanwhile, Mexican fishers have successfully implemented lobster casitas in their native Sian Ka' an region of Mexico, a UNESCO World Heritage site located in the Yucatan state of Quintana Roo similar in latitude to Punta Cana. Casitas are fixed concrete lobster traps that are placed away from sensitive coral reef areas damaged by conventional lobster fishing activities. The Partnership facilitated an exchange program between these Mexican fishers and those of the Punta Cana region to demonstrate how to build a sustainable lobster fishery in Punta Cana that does not damage coral reefs. This has resulted in a management program for the spiny lobster to restore local populations within the reef while preserving the livelihood of the lobster fishers.

Another exchange program involves Venezuelan and American professional sports fly-fishers and commercial fishing operators to study and help train Dominican subsistence fishers, including roles as guides, captains, and boat hands for line and fly-fishing excursions with tourists, as well as to evaluate the viability of catch/picture/release excursions in Punta Cana. Along with government regulation, this program is helping reduce fin fishing pressure on coral reefs while creating alternative economic opportunity for local fishers that allows native fish populations to recover. Working with the Dominican Government Fishing Authority, the program includes formal designation of no-take and controlled-take fishing zones, implementation of fishing licenses, and catch limits on size, species, and seasonality.

The FEPC also initiated a lionfish (Pterois sp.) control program through the commercialization and consumption of this invasive species in restaurants with scientific oversight of the Regional Commission for Lionfish Control. Pterios species are invasive to the Caribbean and consume a broad spectrum of reef fish exacerbating the decline of reef diversity and posing a serious, long-term hazard to the health of the reef. The Foundation purchases lionfish from local fishermen and uses them to prepare special dishes in local restaurants as a means to decrease and control the lionfish population while creating alternative sustainable livelihoods for local fishermen. Creating a seafood market for lionfish may be the only way to control its rapidly expanding populations.

The Foundation also partners with a variety of organizations to conserve critically endangered terrestrial fauna. They have teamed with the Peregrine Fund in an attempt to save the globally endangered Ridgway's Hawk from extinction. These raptors are unique to Hispanola and have diminished to only a small number of breeding pairs restricted to Los Haitises National Park because of hunting and loss of habitat. FEPC is increasing their populations through controlled relocations into the Punta Cana region coupled with a comprehensive environmental monitoring and education program and it is hoped that a viable breeding population will be established in 
the Indigenous Eyes Preserve within five years. This past year, the project recorded the first successful pairing and hatching of a chick from the controlled reintroductions.

Populations of the Hispaniolan hutia (Plagiodontia aedium), a large arboreal rodent, and the Hispanolan solenodon (Solenodon paradoxus), a large, insectivorous, shrew-like mammal are both found only on the island of Hispaniola. Both are believed to be in serious decline as their forest habitat is fragmented throughout the Dominican Republic and Haiti. Led by the Durrell Wildlife Conservation Trust this joint project involving the Hispaniola Ornithological Society, the Zoological Society of London, the Dominican National Zoo, and the Dominican Ministry of Environment has been working with the FEPC to successfully identify the species in the Punta Cana region to calculate conservation measures.

In 2002, the Puntacana Ecological Foundation launched the Iguana Conservation Project to increase the endangered rhinoceros iguana (Fig. 6) population through the protection of existing populations and reintroduction of captive-bred iguanas in the Punta Cana area. There were no endemic populations of $C$. cornuta at that time. Ironically, while captive populations are very high for this striking, diurnal reptile in both zoos and private collections, they are endangered and protected in the wild. Loss of habitat has restricted them to a few small locations in DR. The Foundation has conducted several controlled releases of iguanas and has established regular monitoring of iguana populations in Punta Cana in the hopes of establishing them in this part of their traditional range.

Fig. 6. Rhinoceros iguana (Cyclura cornuta) in captive breeding compound. (C) Puntacana Ecological Foundation)

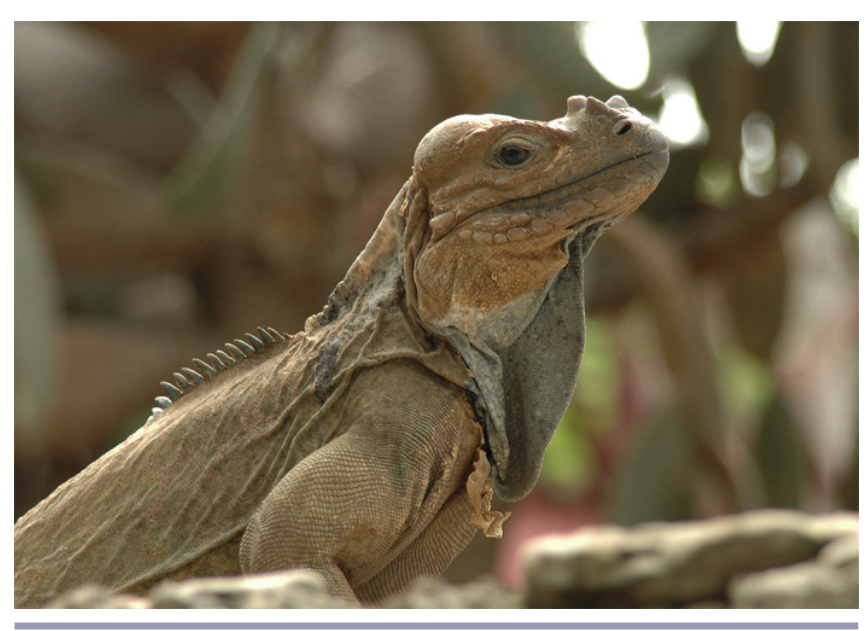

The Puntacana Ecological Foundation has also been actively involved in sustainable agriculture for the past two decades, starting with the planting of endemic fruit trees, which has grown into a large-scale nursery and greenhouses, then pioneering worm composting as part of the Zero Waste
Initiative to capture and compost tons of waste from resort kitchens and gardens into high quality, organic fertilizers and soils, that are then used in their large nursery to grow vegetables year-round and provide local restaurants and community residents with fresh, local produce. They also use the nursery and greenhouses to train local farmers in experimental, high-yield agricultural techniques. FEPC also established apiaries, which have grown to a widespread beekeeping operation now producing hundreds of gallons of honey per year as well as other natural products for sale to support the Foundation's work (Fig. 7). Honeybees are vital pollinators critical to the productivity of agricultural operations.

Fig. 7. Active comb from Puntacana apiaries. (ㄷ Puntacana Ecological Foundation)

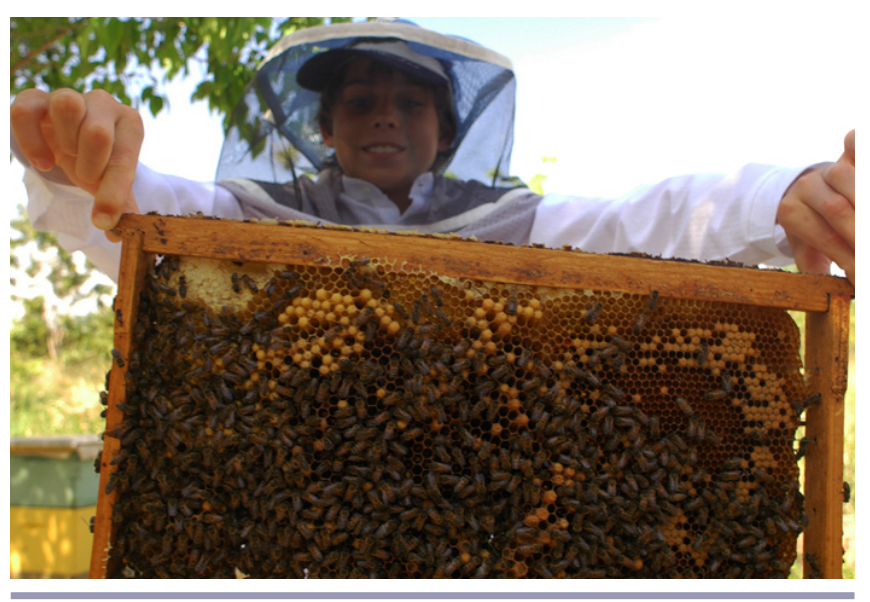

The goal of the Zero Waste Initiative is not just to provide compost for agricultural operations, but to improve the classification of waste at the source to reduce sorting and eliminate landfill practices altogether, redirecting it into $100 \%$ renewable and recyclable production streams. Successful practices toward attaining this goal are already being replicated by other resorts and has evolved into a network of companies outside the resort industry committing to the goals of this program. The federal government is now considering enacting regulations to reduce waste. Jake Kheel, FEPC's Executive Director admits that they were surprised at how widespread the impact this program has been in DR but also expresses that there is still much work to be done.

More effective approaches to dealing with wastewater have become important because of increasing demand for treatment. Interest in the use of macrophytic plants such as water hyacinth has been increasing recently (Aina et al. 2012). Over the past six months, the Foundation has been piloting the use of macrophytes to increase water quality and reduce sludge. They are finding that it both improves treatment and helps reduce operating costs, as well as reducing odor in the 
locations around treatment facilities. Finally, in collaboration with the local Wendy's restaurants, they are now piloting the use of untreated waste cooking oil, i.e., not converted to biodiesel, for generating electricity.

\section{THE FEPC'S INTERFACE WITH SOCIAL AND CULTURAL PROGRAMS}

Whereas the Puntacana Ecological Foundation has been developing environmental programs to address the growth of tourism, Grupo Puntacana recognized early on that the many cultural, economic, and educational problems that arise from expanding tourism trade must be addressed directly for sustainable tourism to be successful. The Puntacana Foundation's (separate from the Puntacana Ecological Foundation) objectives are primarily social, cultural, and educational and just as the FEPC addresses a spectrum of environmental, conservation, and sustainability programs, the Puntacana Foundation supports a range of social needs in Punta Cana and throughout DR and these include:

- Support for regional public and private schools, the Veron Primary School, creation and support of the Puntacana International School, and the Ann and Ted Kheel Polytechnic High School in Punta Cana. This educational system has been created to fill needs in the region for resident resort workers to learn English for as well as the immigrant workers to learn Spanish, trades for new skills needed in resort-oriented enterprises, as well as sustainable practices and competencies for transition to higher education,

- Support for the creation of the Veron Police Department and provide infrastructure for helping local law enforcement cope with urban growth,

- Support for the rehabilitation and expansion of the Primary Care Clinic in Veron, as well as other health services and public health education outreach programs, and

- Support for cultural events and programs that promote sports, history, music, arts, and entrepreneurship, particularly with youth.

Although the two foundations function as separate entities, their activities are complementary and address a spectrum of needs in the region. The success of the FEPC's environmental programs depends on a well-educated, healthy, and secure inhabitants whose basic needs are being met (Fig. 8).

\section{DISCUSSION}

It is evident that the numerous and widespread programs, initiatives, and partnerships of the Grupo Puntacana and the Puntacana Ecological Foundation are intended to address both extant and emerging issues around sustainable tourism. They demonstrate a high degree of integration and foresight into the myriad intersecting problems associated with tourism development in the Caribbean and globally. In terms of how these programs fit into the United Nations essential ideas for integrated sustainable tourism development, it is clear that balancing social and economic objectives with environmentally sound management is the overarching philosophy for the FEPC. The growth and maintenance of these programs over the duration of the Grupo Puntacana's development of a tourism destination indicates that long-term viability and sustainability is an important and useful goal, as well as resulting in reduced operational costs and improved productivity (Stipanuk 2003). The way these programs target specific and salient environmental and social problems indicates a degree of innovation, collaboration with, and leveraging of programs and resources determined to fulfill these goals and indicates they are taking a systemic view of the impacts and the trends in social-ecological and economic systems. As indicated by Sasidharan and Hall (2012) important ideas from the "Dominican Model" can inform other tourism operators and regions, and provide exemplars for advancing sustainable tourism globally, including:

Fig. 8. Jake Kheel (right), Director of the Puntacana Ecological Foundation with Paul Beswick, Director of The Puntacana Foundation (@ Puntacana Ecological Foundation)

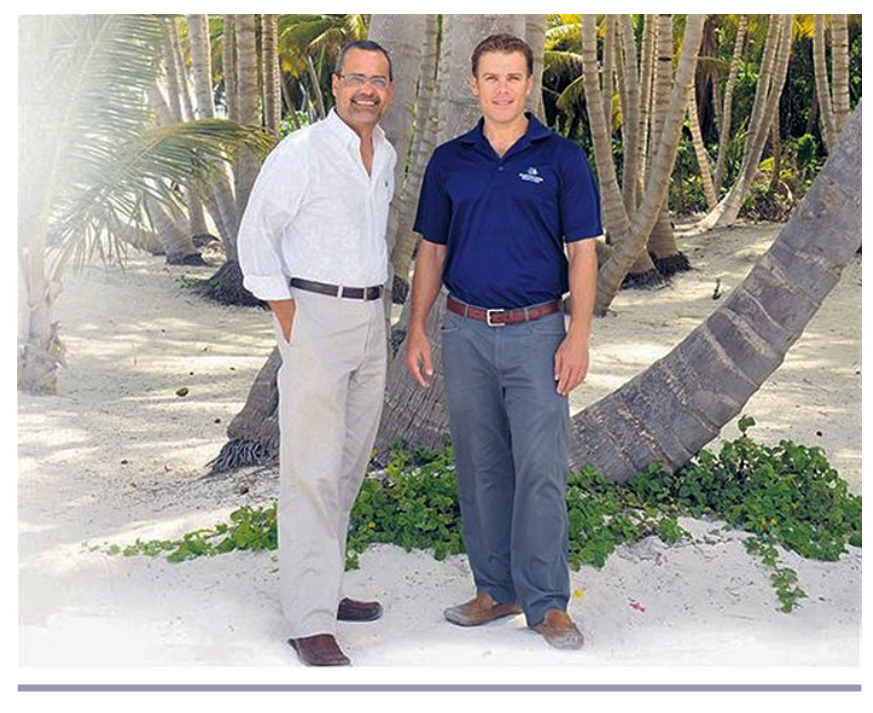

- Preservation of natural resources depends on understanding that complex, dynamic intersecting economic, cultural, ecological, historical, and political systems can only be successful when interventions are adaptive processes,

- Sound environmental management that directly involves stakeholders, seeks opportunity within processes to sustain both human and natural assets, enlists stakeholders and interests, and seeks solutions that are 
well integrated into evolving social, ecological, and economic systems will be better integrated into these systems in the long term,

- Solutions must be seen as ongoing commitment, and works in progress, rather than short-term fixes. Persistence, ingenuity, reflection on effectiveness and attention to both primary and secondary effects will result in more sustainable programs, that can also reduce the economic impact of traditional approaches, e.g., sustainable waste management saves money in the long term over traditional landfill, and

- Embracing the philosophy of "think globally, act locally" must address very specific opportunities and needs while developing far-ranging and highly innovative and integrative solutions that depend on local and global resources and ideas.

Just as the FEPC has been listening to the needs of the communities in which it resides and seeking collaborative solutions, it is well positioned to advocate for an assist others in replicating and expanding these models.

\section{CONCLUSIONS}

The transferability and adaptability of the FEPC's approaches are of interest and potential impact to many classes of tourism operations and provide models that should be disseminated widely to broaden impact and explore efficacy in a spectrum of local and regional conditions. Exploring the potential for the "Dominican Model" to benefit the field, could include:

- Apply emerging systemic and adaptive practices to analyzing and framing their approach and developing indicators that accommodate the dynamics and complexity of the ways human and natural systems couple,

- Formalize the "Dominican Model" in ways that other resort operations could practically and quickly adapt to their particular needs,

- Develop enhanced resources, such as training and exchange programs, materials, and tools to transfer the benefits of this model to other operators, and

- Work closely with regulators and international advocacy organizations to develop new ways to certify resort operators for sustainable practices.

Traditional indicators for sustainable development have been assailed for too narrowly defining the criteria for sustainable development, missing critical aspects of social, economic, or environmental change or conditions, and requiring sophisticated modeling approaches that require specialized training and methods. Even the well-defined Millennium Development Goals of the UN may miss crucial information about positive and negative trends that can inform both specific programs of sustainable development and the evaluation of or generalizable use of those indicators. "Wicked problems," as Rittel and Webber (1973) term them, require a seemingly paradoxical combination of embracing the complexity of the socio-environmental systems in which they reside, along with devising simple and cost-reducing solutions.

The "Dominican Model" as represented by the work of Grupo Puntacana's Puntacana Ecological Foundation may be a good candidate for developing new indicators for sustainable development. As suggested by Schianetz and Kavanaugh (2008), a Modified Sensitivity Model, as originally proposed by Vester (2002), may be a direction to consider, along with novel approaches such as systems and network analyses. The field of sustainable tourism may also be ready for longitudinal research in understanding trends in sustainable tourism that consider resilience in long-term impacts of global recessions, climate change, sea level rise, human migration/urbanization, and other trends that will have significant impacts over longer time frames.

Under the tutelage of Jake Kheel, Executive Director of the Puntacana Ecological Foundation, both the ongoing work in sustainable tourism and the potential for future directions in their work on integrated sustainable development is a useful model and test bed for exemplary program development that contributes significantly to the field of sustainable tourism research and program development. Grupo Puntacana is planning to expand these development principles to other tourism destinations in DR, including Corbanitos, near Santo Domingo.

Responses to this article can be read online at: http://www.ecologyandsociety.org/issues/responses. php/6259

\section{LITERATURE CITED}

Aina, M., N. Kpondjo, J. Adounkpe, D. Chougourou, and M. Moudachirou. 2012. Study of the purification efficiencies of three floating macrophytes in wastewater treatment. International Research Journal of Environmental Sciences 1 (3):37-43.

Chavez, E. 2007. Socio-economic assessment for the management of the Caribbean spiny lobster. Proceedings of the 60th Gulf and Caribbean Fisheries Institute, November 5-9, Punta Cana, Dominican Republic. Florida Fish and Wildlife Conservation Commission, Marine Research Institute, Marathon, Florida.

Frane, A. 2009. Veron community inquiry. Dissertation. Virginia Polytechnic Institute and State University, School of Public and International Affairs, Blacksburg, Virginia, USA. 
Geraldes, F., and M. Vega. 2005. Dominican Republic. Pages 86-99 in P. Miloslavich and E. Klein, editors. Caribbean marine diversity: the known and the unknown. DEStech, Lancaster, Pennsylvania, USA.

Hembd, J., and J. Silberstein. 2011. Sustainable communities: sustainability and community development. Pages 261-278 in J. W. Robinson, Jr. and G. P. Green, editors. Introduction to community development: theory, practice, and servicelearning. Sage, Thousand Oaks, California, USA.

Knudson, D. M., W. R. Chaney and F. A. Reynoso. 1988. Fuelwood and charcoal research in the Dominican Republic: results of the Wood Fuel Development Program. Instituto Superior de Agricultura, Agency for International Development of Science and Technology, Washington, D.C., USA

Liu, Z. 2003. Sustainable tourism development: a critique. Journal of Sustainable Tourism 11(6):459-475. http://dx.doi. org/10.1080/09669580308667216

Michelitsch, V. 2001. Dominican Republic: approaches toward sustainable tourism development: a strategic concept. Dissertation. Department of Economics, University of Applied Sciences, Heilbronn, Germany.

Rittel, H. W. J., and M. M. Webber. 1973. Dilemmas in a general theory of planning. Policy Sciences 4:155-169. http:// dx.doi.org/10.1007/BF01405730

Sasidharan, V., and M. E. Hall. 2012. Dominican resort tourism, sustainability, and millennium development goals. Journal of Tourism Insights 3(1):5. http://dx.doi. org/10.9707/2328-0824.1029

Schianetz, K., and L. Kavanaugh. 2008. Sustainability indicators for tourism destinations: a complex adaptive systems approach using systemic indicator systems. Journal of Sustainable Tourism 16(6):601-628. http://dx.doi. org/10.1080/09669580802159651

Stipanuk, D. 2003. The Punta Cana Resort and Club: a sustainability model in the Caribbean. Report for the World Travel \& Tourism Council, London, UK and The Conference Board, New York, New York, USA.

United Nations Environment Programme (UNEP). 2009. Sustainable coastal tourism: an integrated planning and management approach. Report from the UNEP, Sustainable Production and Consumption Branch, Paris, France.

Vester, F. 2002. The art of interconnected thinking: ideas and tools for a new approach to tackling complexity. Verlag, $\mathrm{GmbH}$, Munich, Germany. 